\title{
The removal of airborne SARS-CoV-2 and other microbial bioaerosols by air filtration on COVID-19 surge units
}

Andrew Conway-Morris $\mathrm{PhD}^{ \pm 1,2}$, Katherine Sharrocks DPhil ${ }^{ \pm 3}$, Rachel Bousfield BMBS ${ }^{ \pm 3,4}$, Leanne Kermack MSc ${ }^{ \pm 5}$, Mailis Maes MPhil ${ }^{5}$, Ellen Higginson $\mathrm{PhD}^{5}$, Sally Forrest BSc ${ }^{5}$, Joana PereiraDias MSc ${ }^{5}$, Claire Cormie ${ }^{5}$, Tim Old MA ${ }^{3}$, Sophie Brooks MSc ${ }^{3}$, Islam Hamed FRCA ${ }^{1}$, Alicia Koenig MBChB ${ }^{1}$, Andrew Turner ${ }^{6}$, Paul White $\mathrm{PhD}^{6,7}$, R. Andres Floto $\mathrm{FRCP}^{8,9}$, Gordon Dougan D.Sc ${ }^{5}$, Effrossyni Gkrania-Klotsas $\mathrm{PhD}^{¥ 3}$, Theodore Gouliouris $\mathrm{PhD}^{¥ 3,4}$, Stephen Baker $\mathrm{PhD}^{5}$, and Vilas Navapurkar FFICM ${ }^{1 *}$

1 The John Farman ICU, Cambridge University Hospitals NHS Foundation Trust, Hills Rd, Cambridge CB2 0QQ, UK

2 University Division of Anaesthesia, Department of Medicine, University of Cambridge School of Clinical Medicine, Cambridge Biomedical Campus, Cambridge, UK

3 Department of Infectious Diseases, Cambridge University Hospitals NHS Foundation Trust, Hills Rd, Cambridge CB2 0QQ, UK

4 Clinical Microbiology Laboratory, Cambridge University Hospitals NHS Foundation Trust, Hills Rd, Cambridge CB2 0QQ, UK

5 Cambridge Institute of Therapeutic Immunology and Infectious Disease, Department of Medicine, University of Cambridge School of Clinical Medicine, Cambridge Biomedical Campus, Cambridge, UK

6 Department of Clinical Engineering, Cambridge University Hospitals NHS Foundation Trust, Cambridge UK

7 Medical Technology Research Centre and School of Medicine, Anglia Ruskin University, Chelmsford, UK

8 Molecular Immunity Unit, University of Cambridge Department of Medicine, MRC-Laboratory of Molecular Biology, Cambridge, UK

9 Cambridge Centre for Lung Infection, Royal Papworth Hospital, Cambridge UK 
${ }^{ \pm}$The following authors contributed equally to this work

$¥$ The following authors contributed equally to this work

* Address for Correspondence

The John Farman ICU, Addenbrooke's Hospital, Hills Rd, Cambridge CB2 0QQ, UK

Vilas.navapurkar@addenbrookes.nhs.uk

\section{Running head}

Removal of airborne SARS-CoV-2

Word count: Summary 243 main text 2,318

\section{Key words}

SARS-CoV-2; COVID-19; hospital infection control; air filtration

\section{Competing interests}

Vilas Navapurkar is the founder, Director, and shareholder of Cambridge Infection

Diagnostics Ltd. Andrew Conway-Morris, Paul White, Gordon Dougan and Stephen Baker are members of the Scientific Advisory Board of Cambridge Infection Diagnostics Ltd.

Theodore Gouliouris has received a research grant from Shionogi. R Andres Floto has received research grants and/or consultancy payments from GSK, AZ, Chiesi, Shionogi, Insmed, Thirty Technology. Effrossyni Gkrania-Klotsas has received a National Institute of Health Research Greenshoots Award

\section{Author contributions}

ACM conceptualisation, methodology, data analysis, writing-original draft

KS investigation, supervision, writing-review and editing

RB investigation, supervision, writing-review and editing 
LK investigation, data analysis, supervision, writing-review and editing

MM investigation, writing-review and editing

EH investigation, data analysis, writing-review and editing

SF investigation, writing-review and editing

JD investigation, writing-review and editing

TO investigation, writing-review and editing

SBr investigation, writing-review and editing

IH investigation, writing-review and editing

AK investigation, writing-review and editing

AT investigation, writing-review and editing

PW conceptualisation, provision of resources, writing-review and editing

AF Provision of resources, writing-review and editing

GD conceptualisation, provision of resources, supervision, writing-review and editing

EG conceptualisation, supervision, investigation, writing-review and editing

TG conceptualisation, supervision, investigation, writing-review and editing

SB conceptualisation, provision of resources, supervision, data analysis, writing-original draft

VN conceptualisation, provision of resources, supervision, data analysis, writing-original draft

\section{Funding}

This work was supported by a Wellcome senior research fellowship to Stephen Baker

(215515/Z/19/Z). Andrew Conway Morris is supported by a Clinician Scientist Fellowship from the Medical Research Council (MR/V006118/1). Mailis Maes and Sally Forrest are funded by the National Institute for Health Research [Cambridge Biomedical Research Centre at the Cambridge University Hospitals NHS Foundation Trust]. The views expressed are those of the authors and not necessarily those of the NHS, the NIHR or the Department of Health and Social Care.

The funders had no role in the design and conduct of the study; collection, management, analysis, and interpretation of the data; preparation, review, or approval of the manuscript; and decision to submit the manuscript for publication. 
medRxiv preprint doi: https://doi.org/10.1101/2021.09.16.21263684; this version posted September 22, 2021. The copyright holder for this preprint (which was not certified by peer review) is the author/funder, who has granted medRxiv a license to display the preprint in perpetuity.

It is made available under a CC-BY 4.0 International license .

The study was registered as a service evaluation with Cambridge University Hospitals NHS

Foundation Trust (Service Evaluation Number PRN 9798). 


\section{Summary}

Background

The COVID-19 pandemic has overwhelmed the respiratory isolation capacity in hospitals; many wards lacking high-frequency air changes have been repurposed for managing patients infected with SARS-CoV-2 requiring either standard or intensive care. Hospital-acquired COVID-19 is a recognised problem amongst both patients and staff, with growing evidence for the relevance of airborne transmission. This study examined the effect of air filtration and ultra-violet (UV) light sterilisation on detectable airborne SARS-CoV-2 and other microbial bioaerosols.

\section{Methods}

We conducted a crossover study of portable air filtration and sterilisation devices in a repurposed ‘surge' COVID ward and 'surge' ICU. National Institute for Occupational Safety and Health (NIOSH) cyclonic aerosol samplers and PCR assays were used to detect the presence of airborne SARS-CoV-2 and other microbial bioaerosol with and without air/UV filtration.

Results

Airborne SARS-CoV-2 was detected in the ward on all five days before activation of air/UV filtration, but on none of the five days when the air/UV filter was operational; SARS-CoV-2 was again detected on four out of five days when the filter was off. Airborne SARS-CoV-2 was infrequently detected in the ICU. Filtration significantly reduced the burden of other microbial bioaerosols in both the ward ( 48 pathogens detected before filtration, two after, $p=0.05$ ) and the ICU (45 pathogens detected before filtration, five after $p=0.05$ ).

\section{Conclusions}

These data demonstrate the feasibility of removing SARS-CoV-2 from the air of repurposed 'surge' wards and suggest that air filtration devices may help reduce the risk of hospital-acquired SARS-

\section{$\mathrm{CoV}-2$.}

\section{Funding}

Wellcome Trust, MRC, NIHR 


\section{Introduction}

2 During the COVID-19 pandemic 'general' hospital wards in the UK were rapidly repurposed into

3 'surge' wards and intensive care units (ICU), which lacked the capacity for high frequency air-

4 changes. Airborne dissemination is likely an important transmission route for SARS-CoV-2 ${ }^{1}$, with

5 SARS-CoV-2 RNA being detected in air samples from wards managing COVID-19 patients ${ }^{2,3}$.

6 Despite the use of appropriate personal protective equipment (PPE) that filter medium and large size

7 droplets, there are multiple reports of patient-to-healthcare worker transmission of SARS-CoV-2 ${ }^{4,5,6 \text {, }}$

8 potentially through the inhalation of viral particles in small $(<5 \mu \mathrm{M})$ aerosols ${ }^{7}$. Furthermore,

9 nosocomial acquisition of COVID-19 has continued to blight healthcare systems despite the

10 systematic introduction of patient and healthcare worker asymptomatic screening programmes ${ }^{8}$. There

11 is a need to improve the safety for healthcare workers and patients during the pandemic by decreasing

12 the potential for the airborne transmission of SARS-CoV-2 ${ }^{7}$. Engineering solutions that improve

13 ventilation with provision of UV light sterilisation are considered a more effective intervention in the

14 hierarchy of controls against transmissible infections compared to enhanced respiratory protective

15 equipment ${ }^{9,10}$. Portable air filtration systems, that combine high efficiency particulate filtration and

16 ultraviolet (UV) light sterilisation, may be a scalable solution for removing respirable SARS-CoV-2.

17 A recent review by the UK Scientific Advisory Group for Emergencies modelling group found

18 limited data regarding the effectiveness of such devices ${ }^{11}$, which is consistent with findings from two

19 recent systematic reviews ${ }^{12,13}$. Most of the testing of such systems has been physical device

20 validation using inorganic particles or removal of bacterial bioaerosols in controlled test environments

$21{ }^{12,13}$. Here we present the first data providing evidence for the removal of SARS-CoV-2 and microbial

22 bioaerosols from the air using portable air filters with UV sterilisation on a COVID-19 'surge' ward

23 during the ongoing pandemic.

\section{Methods}

26 Setting

27 The study was conducted in two repurposed COVID-19 units in Addenbrooke's Hospital, Cambridge,

28 UK in January/February 2021 when the alpha variant (lineage B1.1.7) comprised $>80 \%$ of circulating 
29 SARS-CoV-2 ${ }^{8}$. One area was a 'surge ward' (ward) managing patients requiring simple oxygen

30 therapy or no respiratory support, the second was a 'surge ICU' (ICU) managing patients requiring

31 invasive and non-invasive respiratory support. The ward was a fully occupied four-bedded bay (Fig.

32 1A). The ICU was fully occupied five-bedded bay, with a super-capacity sixth occupied bed used in

33 week 2 (Fig. 1B).

In the ward we installed an AC1500 HEPA14/UV steriliser (Filtrex, Harlow, UK), whilst in the ICU we installed a Medi 10 HEPA13/UV steriliser (Max Vac, Zurich, Switzerland) (supplemental methods). The air filters were placed in fixed positions before the initiation of the three-week study period (Fig. 1), switched on at the beginning of week two and run continuously from Sunday to

39 Sunday for 24 hours per day, providing approximately 5-10 room-volume filtrations per hour in each

40 location. As the devices do not meet medical device electrical safety standards (EN60601) they were

41 operated at a distance of $\geq 1.5$ metres from any patient.

\section{Study design}

43 We performed a crossover evaluation, with the primary outcome being detection of SARS-CoV-2

44 RNA in the various size fractions of the air samples. Air sampling was conducted using National

45 Institute for Occupational Safety and Health (NIOSH) BC 251 two-stage cyclone aerosol samplers ${ }^{12}$

46 (Donated by B Lindsley, Centers for Disease Control, Atlanta), operated in accordance with previous

47 studies demonstrating capture of airborne viruses (supplemental methods) $)^{2,14-18}$. Air samplers were

48 assembled daily with a sampler left in a sealed bag as a control. Samplers placed adjacent to the air

49 filter inlet and the other at approximately four meters and no closer than two meters to patients (Fig.

50 1). In ICU two distant samplers were used, one mounted at head height and one at bed height.

52 The samplers were operated on weekdays ( $0815 \mathrm{hrs}$ to $1415 \mathrm{hrs})$ for three consecutive weeks. After

53 sampling, the samplers were disassembled using sterile technique and the filter papers were

54 transferred to $15 \mathrm{ml}$ Falcon tubes. The samples were processed then stored at $-80^{\circ} \mathrm{C}$ until analysis.

55 The samplers were washed with $80 \%$ ethanol and demineralised water. 


\section{Pathogen detection}

58 Nucleic acids were extracted from each NIOSH sampler component (tubes containing large aerosols,

59 medium aerosols, and filter), as previously described ${ }^{19}$. Details of the RT-qPCR for SARS-CoV-2 and

60 multiplex qPCR assays for a range of respiratory and other bacterial, viral, and fungal pathogens are

61 in the supplemental section.

\section{Statistical analyses}

64 Differences in the number of pathogens detected when air filter was on and off were compared by

65 Mann-Whitney U-test. Statistical significance was inferred when $p$ values were $\leq 0.05$. Graphs were

66 generated in R studio.

67

68 The study was registered as a service evaluation with Cambridge University Hospitals NHS

69 Foundation Trust (Service Evaluation Number PRN 9798).

\section{Results}

72 Removal of SARS-CoV-2 by air filtration on surge ward

73 For the duration of the study ( $18^{\text {th }}$ January to $5^{\text {th }}$ February) the beds in the ward and ICU were at

$74100 \%$ occupancy, with 15 patients admitted to the ward and 14 admitted to the ICU over the three-

75 week sampling period (7, 4, 4 in weeks 1-3 in the ward and 6, 5, 3 in the ICU, respectively). All

76 patients were symptomatic and tested positive for SARS-CoV-2 RNA from a respiratory sample

77 before admission. Patients in the ICU were managed with non-invasive mask ventilation, high flow

78 nasal oxygen or invasive ventilation via endotracheal tube or tracheostomy. Patients in the ward were

79 spontaneously ventilating with simple oxygen therapy or no respiratory support and no aerosol-

80 generating procedures performed.

82 In the ward, during the first week whilst the air filter was inactive, we were able to detect SARS-CoV-

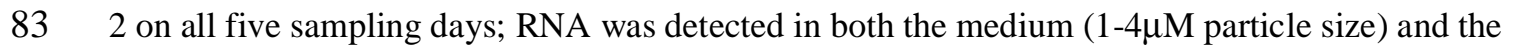


84 large ( $>4 \mu \mathrm{M}$ particle size) particulate fractions (Fig. 2A). SARS-CoV-2 RNA was not detected in the

85 small $(<1 \mu \mathrm{M})$ particulate filter. The air filter was switched on in week two and run continuously; we

86 were unable to detect SARS-CoV-2 RNA in any of the sampling fractions on any of the five testing

87 days. These initial observations provided evidence for the removal of SARS-CoV-2 via the air filter

88 system, albeit at high baseline $\mathrm{C}_{T}$ values. To confirm this observation, we completed the study by

89 repeating the sampling with an inactive air filter. As in week one, we were able to detect SARS-CoV-

902 RNA in the medium and the large particulate fractions on $3 / 5$ days of sampling (a sample without

91 tube size indicated tested positive on day 5) (Fig. 2A). We did not detect SARS-CoV-2 RNA from the

92 control sampler.

Removal of additional bioaerosols by air filtration on surge ward

95 We subjected the extracted nucleic acid preparations to high-throughput qPCR using a Biomark HD

96 system to detect a range of viral, bacterial, and fungal targets. In the week one samples, we detected

97 nucleic acid from multiple viral, bacterial, and fungal pathogens on all sampling days (Fig. 2B). In

98 contrast, when the air filter was switched on, we detected yeast targets only on a single day, with a

99 significant reduction $(p=0.05)$ in microbial bioaerosols when the air filter was operational (Fig. 2C).

100 Using this high-throughput approach, SARS-CoV-2 RNA was detected on 4/5 days tested in week 1

101 but was again absent in week 2. We were unable to generate multiplex data for week three due to

102 sample degradation after storage of sample following SARS-CoV-2 RNA amplification.

105 In contrast to the ward, we found limited evidence of airborne SARS-CoV-2 in weeks one and three

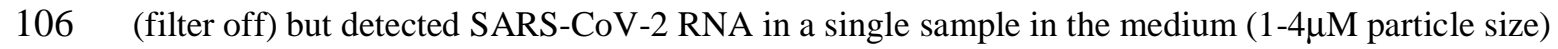

107 particulates on week 2 (filter on) (Fig. 3A). This contrary result did not reflect a general lack of

108 bioaerosols in the ICU, which demonstrated a comparable quantity and array of pathogen associated

109 nucleic acids to that seen in the unfiltered ward air on week one (Fig. 3B). Again, the use of the air

110 filtration device significantly $(p=0.05)$ reduced the microbial bioaerosols (Fig 3C); with only three 
111 organism types detected on two of the sampling days (Fig 3B). SARS-CoV-2 RNA was only detected

112 once on the high-throughput qPCR assay, during week one.

\section{Discussion}

115 Our study represents the first report of successful removal of airborne SARS-CoV-2 in a hospital

116 environment using combined air filtration and UV sterilisation technology. Specifically, we provide

117 evidence for the circulation of SARS-CoV-2 in a ward within airborne droplets of $>1 \mu \mathrm{M}$. Droplets of

$118 \quad 1-4 \mu \mathrm{M}$ are likely a key vehicle for SARS-CoV-2 transmission, as they can remain airborne for a

119 prolonged period. They are also readily respirable and can deposit in the distal airways. Recent data

120 has shown that exertional respiratory activity, such as that seen in patients with COVID-19, increases

121 the release of 1-4 $\mu \mathrm{M}$ respiratory aerosols, whilst conventionally defined 'aerosol generating

122 procedures' such as high flow nasal oxygen and non-invasive ventilation actively reduce aerosol

123 generation during exertion ${ }^{20}$. These data are consistent with our observations, suggesting that

124 precautions to remove aerosolisation may be more important in conventional wards than in well

125 defined 'aerosol risk areas'. We also found a low burden of SARS-CoV-2 in the air on the ICU. This

126 observation, combined with the higher level of aerosol protection worn by ICU staff, may explain

127 why staff in these areas appear to be at significantly lower risk of acquiring COVID than those

128 working on wards ${ }^{21}$.

130 The sampling and detection of airborne viruses poses several technological challenges, and although

131 several approaches have been developed, there remains no agreed standard for their use or

132 interpretation ${ }^{22}$. However, the detection of SARS-CoV-2 RNA by RT-qPCR (albeit at a high $\mathrm{C}_{T}$

133 value), and the lack of detection during use of an air filtration/UV sterilisation system, adds to a

134 growing body of evidence implicating the airborne transmission of SARS-CoV-2 ${ }^{1}$. The detection of

135 SARS-CoV-2 RNA in the air of a ward managing patients with COVID-19 intimates that this is a key

136 mechanism by which healthcare professionals could become infected during patient care. The removal

137 of airborne viral particles and other pathogens may help reduce the likelihood of hospital-acquired 
138 respiratory infections. This reduction may be by both decreasing the load of respirable particles and

139 by removal of larger droplets that can facilitate fomite-associated spread ${ }^{22}$. The clearance of

140 bioaerosol was not restricted to SARS-CoV-2. A range of bacteria, yeasts, and other respiratory

141 viruses with pathogenic potential were detected in the air of both rooms in the first week, with their

142 burden significantly reduced during air filtration. Although the impact of air filtration on nosocomial

143 infection is uncertain ${ }^{23}$, the broad range of pathogens removed in this study suggests potential for

144 benefit beyond removal of SARS-CoV-2.

146 There are several potential explanations for the lower detection of SARS-CoV-2 in air of an ICU.

147 These include a later stage of disease during which viral replication is less pronounced ${ }^{24}$, higher viral

148 loads in the lower rather than upper respiratory tract in critically ill patients ${ }^{25}$ and use of respiratory

149 devices, which reduce aerosol generation ${ }^{20}$. The reduction in microbial bioaerosols found in ICU

150 during the week of the air filtration system provides confidence that the device was similarly effective

151 to that used on the ward, despite the infrequent detection of SARS-CoV-2.

153 A recent systematic review of both static and portable air filtration, which also assessed relevant

154 building codes and guidelines ${ }^{12}$, identified no robust studies of air filtration. Although multiple

155 building codes propose air filtration to protect vulnerable patients and to reduce risks of transmission

156 of airborne diseases, these have not been updated in light of COVID-19 $9^{12}$. Mousvai and colleagues

157 identified several studies demonstrating the capacity of air filtration to reduce inert, fungal, and

158 bacterial bioaerosols in experimental and clinical contexts. These findings are consistent with our

159 report, but previous data originate from fixed rather than portable air filtration devices. No reports of

160 SARS-CoV-2 removal were identified. A further recent review focussed solely on portable air

161 filters ${ }^{13}$, with studies demonstrating the removal of inert particles and deliberately aerosolised

162 bacteria, again no reports of SARS-CoV-2 removal were identified. The Centres for Disease Control

163 recommend the consideration of portable HEPA-based air filters; this recommendation applies only to

164 dental facilities where there is deemed to be a high risk of aerosol generation ${ }^{26}$. 
medRxiv preprint doi: https://doi.org/10.1101/2021.09.16.21263684; this version posted September 22, 2021. The copyright holder for this

It is made available under a CC-BY 4.0 International license .

166 This study has limitations, being conducted rapidly in active wards during an ongoing pandemic. The

167 evaluation was conducted in two rooms and there are no data defining the optimal air changes

168 required to remove detectable pathogens with the specified devices. Given the large volume of air

169 within the room and the stability of viruses in the sampling fluid, it was predictable that the amount of

170 SARS-CoV-2 detected via qPCR would be minimal, as evidenced by high $\mathrm{C}_{T}$ values. Therefore, we

171 cannot categorically state that there was circulating infectious virus. RNA is sufficient to suggest the

172 virus was present and it has been shown that aerosolised virus can remain infectious for $>3$ hours ${ }^{27,28}$;

173 additionally, air sampling devices can artefactually reduce the apparent viability of sampled virus.

174 Negative results from the control sampler, and the striking but reversible effect of the air filtration

175 devices, suggest these are not false positive detections and we cannot exclude the risk of airborne

176 infection. Future studies should examine whether air filtration devices, such as those used here, have

177 an impact on healthcare professional and patient focussed outcomes, including measuring

178 infection/exposure as an endpoint, as well as assessing potential harm, such as noise, reduced ambient

179 humidity or impact on delivery of care.

180

181 In conclusion, we were able to detect airborne SARS-CoV-2 RNA in a repurposed COVID-19 'surge

182 ward' and found that air filtration can remove SARS-CoV-2 RNA below the limit of qPCR detection.

183 SARS-CoV-2 was infrequently detected in the air of a 'surge ICU'; however, the device retained its

184 ability to reduce microbial bioaerosols. Our data is highly indicative of aerosolised SARS-CoV-2

185 circulating in areas that are not classically considered 'aerosol risk areas'. Furthermore, portable air

186 filtration devices can mitigate the reduced availability of airborne infection isolation facilities when

187 surges of COVID-19 patients overwhelm healthcare resources. The use of such systems may provide

188 additional safety for those that are of high exposure risk to respiratory pathogens such as SARS-CoV-

1892.

190

191

192

193 
medRxiv preprint doi: https://doi.org/10.1101/2021.09.16.21263684; this version posted September 22, 2021. The copyright holder for this preprint (which was not certified by peer review) is the author/funder, who has granted medRxiv a license to display the preprint in perpetuity.

It is made available under a CC-BY 4.0 International license .

\section{References}

195 1. Greenhalgh T, Jimenez JL, Prather KA, Tufekci Z, Fisman D, Schooley R. Ten scientific

196 reasons in support of airborne transmission of SARS-CoV-2. Lancet. 2021;397(10285):1603-

$197 \quad 1605$

198

199

2. Chia PY, Coleman KK, Tan YK, et al. Novel Coronavirus Outbreak Research Team. Detection of air and surface contamination by SARS-CoV-2 in hospital rooms of infected patients. Nat

202

3. Zhou J, Otter JA, Price JR, et al. Investigating SARS-CoV-2 surface and air contamination in an acute healthcare setting during the peak of the COVID-19 pandemic in London. Clin Infect Dis. 2020 Jul 8:ciaa905.

4. Nguyen LH, Drew DA, Graham MS, et al. Coronavirus Pandemic Epidemiology Consortium.

5. Illingworth C, Hamilton W, Warne B, et al. Superspreaders drive the largest outbreaks of hospital onset COVID-19 infection. OSF Preprints, 15 Feb. 2021. https://doi.org/10.31219/osf.io/wmkn3 Risk of COVID-19 among front-line health-care workers and the general community: a prospective cohort study. Lancet Public Health. 2020;5:e475-e483

7. Fennelly KP. Particle sizes of infectious aerosols: implications for infection control. Lancet Respir Med. 2020;8:914-924.

8. Meredith LW, Hamilton WL, Warne B, et al. Rapid implementation of SARS-CoV-2 sequencing to investigate cases of health-care associated COVID-19: a prospective genomic surveillance study. Lancet Infect Dis. 2020 ;20:1263-1271

9. National Institute for Occupational Safety and Health National Institute for Occupational 
medRxiv preprint doi: https://doi.org/10.1101/2021.09.16.21263684; this version posted September 22, 2021. The copyright holder for this preprint (which was not certified by peer review) is the author/funder, who has granted medRxiv a license to display the preprint in perpetuity.

It is made available under a CC-BY 4.0 International license .

230

231

232

233

234

235

236

237

238

239

240

241

242

243

244

245

246

247

248

249

250

251

252

253

254

255

256

257

258

259

260

261

262

263

264

265

266

10. Morawska L, Allen J, Bahnfleth W, et al. A paradigm shift to combat indoor respiratory infection. Science. 2021;372:689-691

11. UK scientific advisory group for emergencies. Potential application of air cleaning devices and personal decontamination to manage transmission of COVID-19, 4 November 2020 (https://www.gov.uk/government/publications/emg-potential-application-of-air-cleaningdevices-and-personal-decontamination-to-manage-transmission-of-covid-19-4-november2020)

12. Mousavi ES, Kananizadeh N, Martinello RA, Sherman JD. COVID-19 Outbreak and Hospital Air Quality: A Systematic Review of Evidence on Air Filtration and Recirculation. Environ Sci Technol. 2021;55:4134-4147.

13. Liu DT, Phillips KM, Speth MM, Besser G, Mueller CA, Sedaghat AR. Portable HEPA Purifiers to Eliminate Airborne SARS-CoV-2: A Systematic Review. Otolaryngol Head Neck Surg. 2021:1945998211022636

14. Lindsley WG, Schmechel D, Chen BT. A two-stage cyclone using microcentrifuge tubes for personal bioaerosol sampling. J Environ Monit. 2006 ;8:1136-42.

15. Killingley B, Greatorex J, Digard P, et al The environmental deposition of influenza virus from patients infected with influenza A(H1N1)pdm09: Implications for infection prevention and control. J Infect Public Health. 2016;9:278-88.

16. Coleman KK, Sigler W V. Airborne Influenza A Virus Exposure in an Elementary School. Sci Rep. 2020 Feb 5;10:1859.

17. Blachere FM, Lindsley WG, Slaven JE, et al. Bioaerosol sampling for the detection of aerosolized influenza virus. Influenza Other Respir Viruses. 2007;1:113-20

18. Blachere FM, Lindsley WG, Pearce TA, et al. Measurement of airborne influenza virus in a hospital emergency department. Clin Infect Dis. 2009;48:438-40.

19. Sridhar S, Forrest S, Kean I, et al. A blueprint for the implementation of a validated approach for the detection of SARS-Cov2 in clinical samples in academic facilities. Wellcome Open Res. 2020;5:110 
medRxiv preprint doi: https://doi.org/10.1101/2021.09.16.21263684; this version posted September 22, 2021. The copyright holder for this preprint (which was not certified by peer review) is the author/funder, who has granted medRxiv a license to display the preprint in perpetuity.

It is made available under a CC-BY 4.0 International license .

267

268

269

270

271

272

273

274

275

276

277

278

279

280

281

282

283

284

285

286

287

288

289

290

291

292

293

294

295

296

297

298

299

300

301

302

20. Wilson NM, Marks GB, Eckhardt A, et al. The effect of respiratory activity, non-invasive respiratory support and facemasks on aerosol generation and its relevance to COVID-19. Anaesthesia. 2021 Mar 30. doi: 10.1111/anae.15475. Epub ahead of print.

21. Shields A, Faustini SE, Perez-Toledo M, et al SARS-CoV-2 seroprevalence and asymptomatic viral carriage in healthcare workers: a cross-sectional study.

Thorax 2020;75:1089-1094

22. Stockwell RE, Ballard EL, O'Rourke P, Knibbs LD, Morawska L, Bell SC. Indoor hospital air and the impact of ventilation on bioaerosols: a systematic review. J Hosp Infect.

2019;103:175-184.

23. Eckmanns T., Ruden H., Gastmeier P. The influence of high-efficiency particulate air filtration on mortality and fungal infection among highly immunocompromised patients: a systematic review. J Infect Dis. 2006;193:1408-1418

24. Wölfel R, Corman VM, Guggemos W, et al. Virological assessment of hospitalized patients with COVID-2019. Nature. 2020;581:465-469

25. Hamed I, Shaban N, Nassar M, et al. Paired Nasopharyngeal and Deep Lung Testing for Severe Acute Respiratory Syndrome Coronavirus-2 Reveals a Viral Gradient in Critically Ill Patients: A Multicenter Study. Chest. 2021;159:1387-1390.

26. Centers for Disease Control and Prevention [Internet]. Atlanta: The Centers. Interim Infection Prevention and Control Guidance for Dental Settings During the COVID-19 Response. Available from: https://www. cdc.gov/coronavirus/2019-ncov/hcp/dental-settings. html.

27. Fears AC, Klimstra WB, Duprex P, et al. Persistence of Severe Acute Respiratory Syndrome Coronavirus 2 in Aerosol Suspensions. Emerg Infect Dis. 2020 Sep;26(9):2168-71.

28. N van Doremalen N, Bushmaker T, Morris DH, et al. Aerosol and Surface Stability of SARSCoV-2 as Compared with SARS-CoV-1. N Engl J Med. 2020;382(16):1564-1567. 


\section{$304 \quad$ Figure legends}

305

306 Figure 1. Location of the air filters and room layout.

307 A) Layout of the room on the 'surge' ward with four beds. B) Layout on the 'surge' ICU with six beds

308 including the addition of a further bed to increase occupancy (labelled with red box). Locations of the

309 NIOSH air samplers indicated by *. The air filters were installed in the marked locations and set to

310 operate at $1000 \mathrm{~m}^{3} /$ hour. The room's volumes are approximately $107 \mathrm{~m}^{3}$ and $195 \mathrm{~m}^{3}$ respectively.

311 Fresh air was not supplied or extracted in these areas.

313 Figure 2. Bioaerosol detection in specific air sampler fractions over the three-week testing period on 314 the 'surge' ward.

315 A) $\mathrm{C}_{T}$ values for SARS-CoV-2 qPCR on air sample fractions collected daily from the ward. Colours

316 indicate the specific component of the sampler where SARS-CoV-2 was detected. Components

317 collected aerosols dependent on size fractions; large $>4 \mu \mathrm{m}$, medium1-4 $\mu \mathrm{m}$, small $<1 \mu \mathrm{m}$. B) Daily

318 detection of fungal, bacterial and viral bioaerosols detected by high-throughput qPCR collected during

319 weeks one (filter off) and two (filter on). The differences in $\mathrm{C}_{T}$ values between the regular qPCR (A)

320 and high-throughput qPCR (B) are a function of the microfluidics technology, and do not reflect

321 higher bioaerosol burdens. C) Stacked bar chart showing collated total number of bioaerosol

322 detections during weeks one (filter off) and two (filter on). ${ }^{*} p=0.05$ by Mann-Whitney U test.

324 Figure 3. Bioaerosol detection in specific air sampler fractions over the three-week testing period on 325 the 'surge' ICU.

326 A) $\mathrm{C}_{T}$ value for the single qPCR SARS-CoV-2 detection on day 9 (week 2 ) in the medium (1-4 $\mu \mathrm{m}$

327 particle size) fraction. B) Daily detection of fungal, bacterial and viral bioaerosol detected by high-

328 throughput qPCR collected during weeks one (filter off) and two (filter on). The differences in $\mathrm{C}_{T}$

329 values between the regular qPCR (A) and high-throughput qPCR (B) are a function of the 
medRxiv preprint doi: https://doi.org/10.1101/2021.09.16.21263684; this version posted September 22, 2021. The copyright holder for this preprint (which was not certified by peer review) is the author/funder, who has granted medRxiv a license to display the preprint in perpetuity.

It is made available under a CC-BY 4.0 International license .

330 microfluidics technology, and do not reflect higher bioaerosol burdens. C) Stacked bar chart showing

331 collated total number of bioaerosol detections during weeks one (filter off) and two (filter on).

$332 * p=0.05$ by Mann-Whitney U test.

333

334 

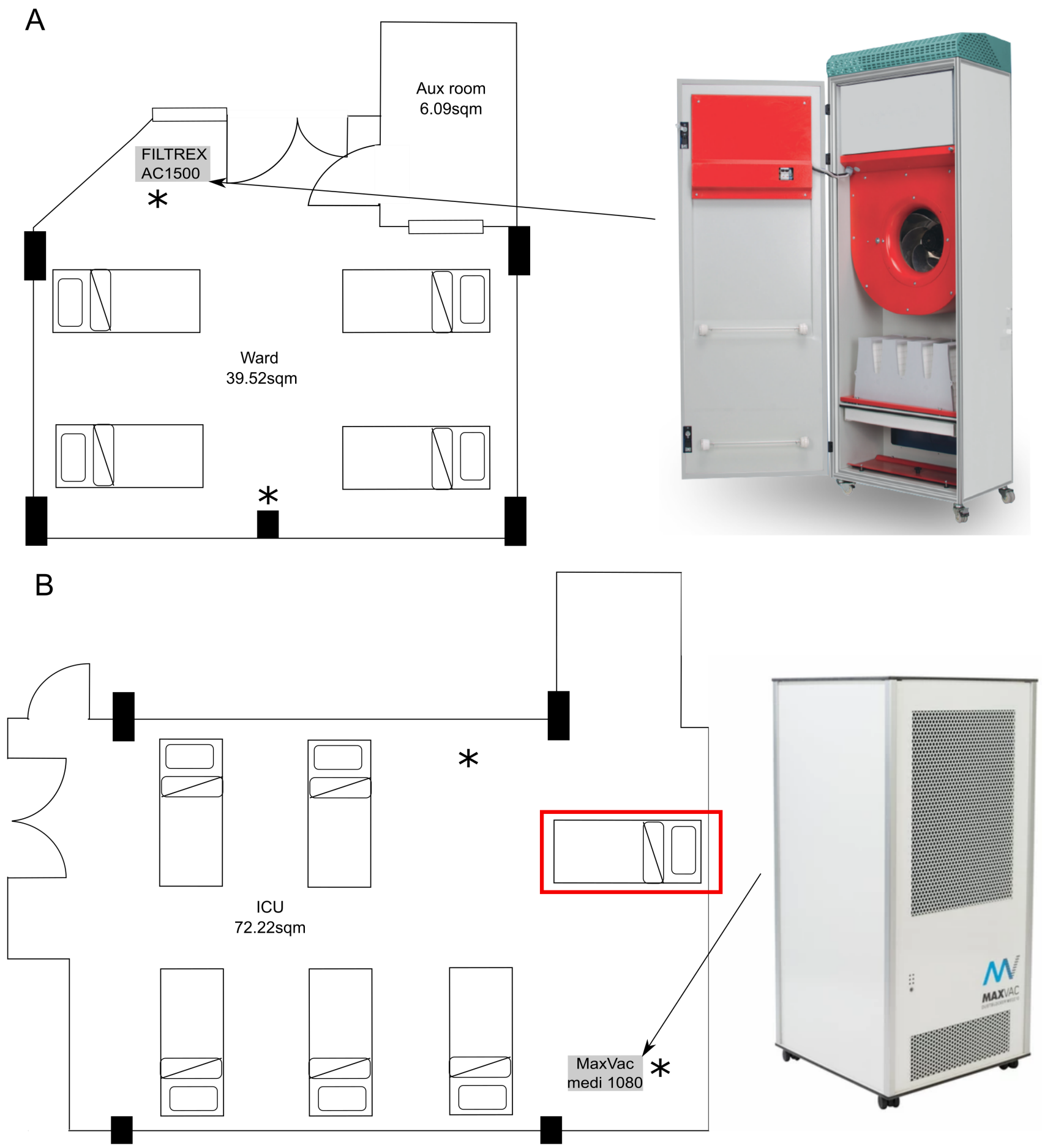

Figure 1. Location of the air filters and room layout.

A) Layout of the room on the 'surge' ward with four beds. B) Layout on the 'surge' ICU with six beds including the addition of the additional bed to increase occupancy (labelled with rad box). Locations of the NIOSH air samplers indicated by *. The air filters were installed in the marked locations and set to operate at $1000 \mathrm{~m}^{3} / \mathrm{hour}$. The rooms volumes are approximately $107 \mathrm{~m}^{3}$ and $195 \mathrm{~m}^{3}$ respectively. Fresh air was not supplied or extracted in these areas. 
A

medRxiv preprint doi: https://doi.org/10.1101/2021.09.16.21263684; this version posted September 22, 2021. The copyright holder for this preprint (which was notrcertified by peer review) is the author/funder, who has granted medRxiv avlicense to display the preprint in perpetuity.

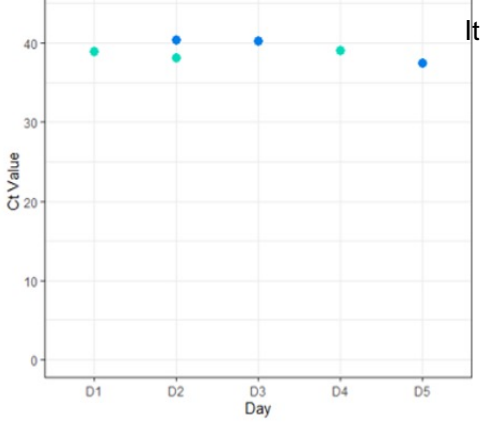

B

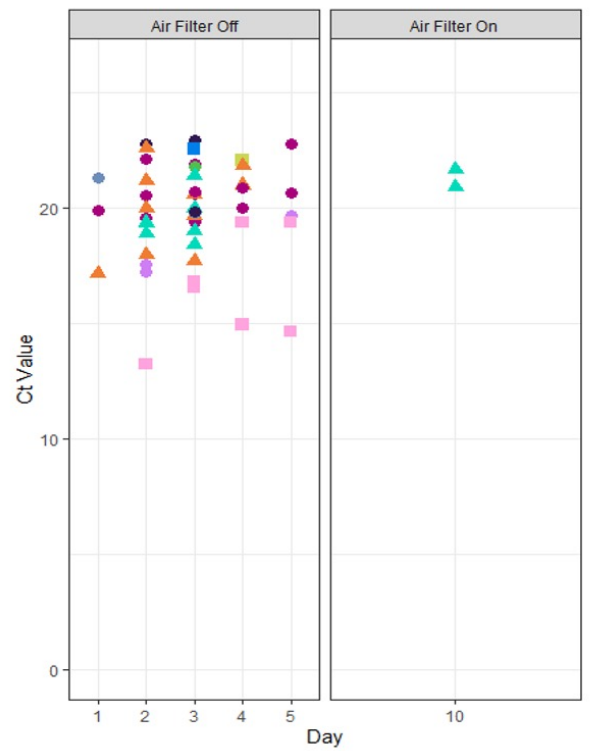

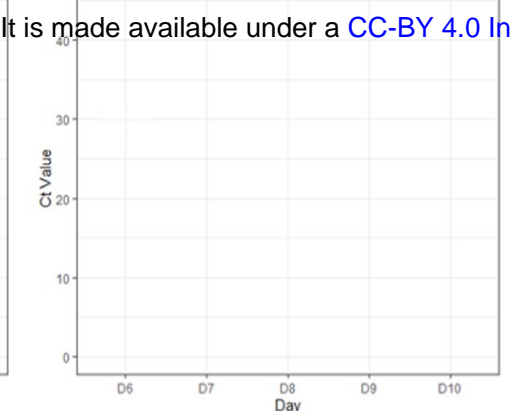

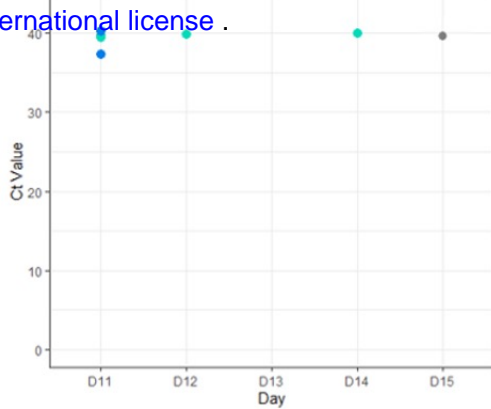

Aerosol Fraction

- Large

Medium

Small

- Unlabelled

Ward

- co
Bioaerosol Classification

- Bacteria

- Fungi

Bioaerosol Detected

- Candida spp.

- CoN Staph

- E. coli

- E. faecalis

- Fungal $18 \mathrm{~S}$

- HPIV3

- HSV1

- P. mirabilis

- S. epidermidis

- SARS-CoV-2

\section{C}

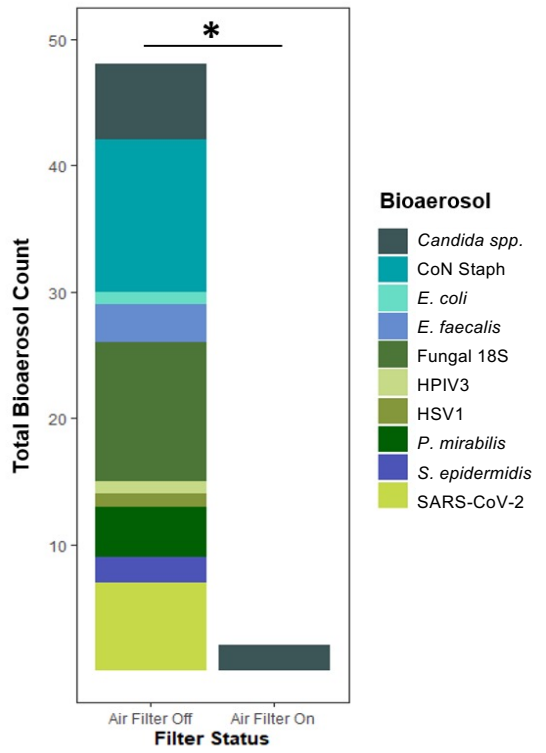

Figure 2. Bioaerosol detection in specific air sampler fractions over the three-week testing period on the 'surge' ward.

A) $\mathrm{C}_{T}$ values for SARS-CoV-2 qPCR on air sample fractions collected daily from the ward. Colours indicate the specific component of the sampler where SARS-CoV-2 was detected. Components collected aerosols dependent on size fractions; large $>4 \mu \mathrm{m}$, medium1-4 $\mu \mathrm{m}$, small $<1 \mu \mathrm{m}$. B) Daily detection of fungal, bacterial and viral bioaerosols detected by high-throughput qPCR collected during weeks one (filter off) and two (filter on). The differences in $\mathrm{C}_{T}$ values between the regular qPCR (A) and high-throughput qPCR (B) are a function of the microfluidics technology, and do not reflect higher bioaerosol burdens. C) Stacked bar chart showing collated total number of bioaerosol detections during weeks one (filter off) and two (filter on). ${ }^{*} p=0.05$ by Mann-Whitney U test. 


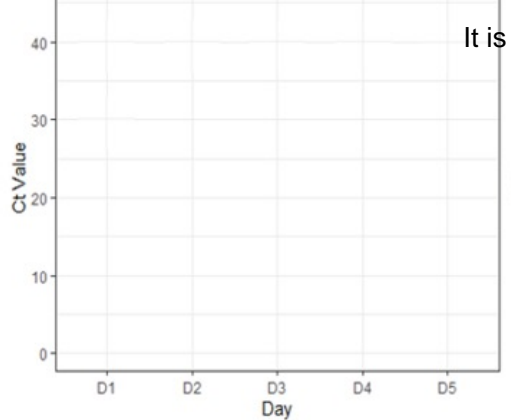

B

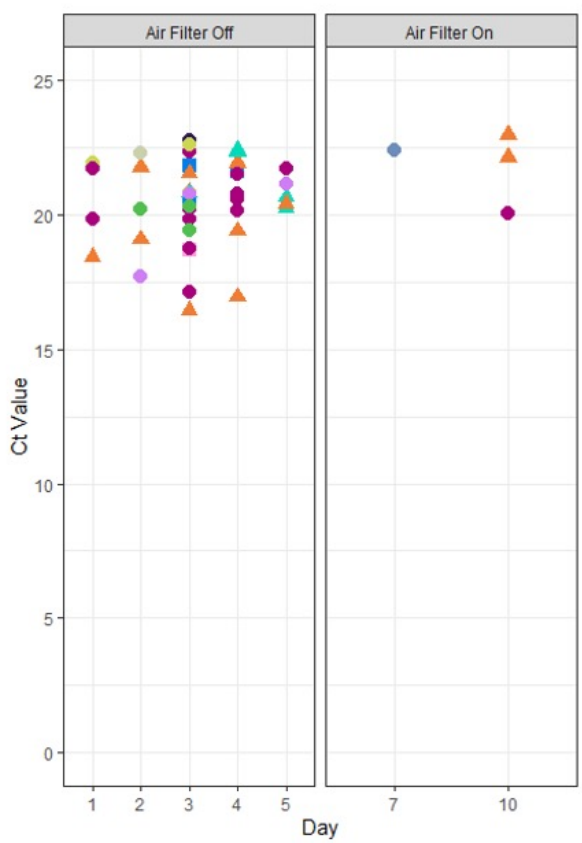

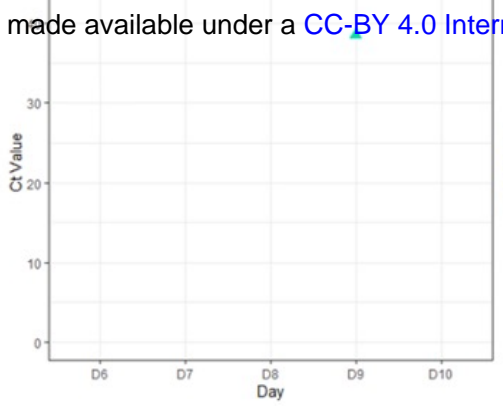

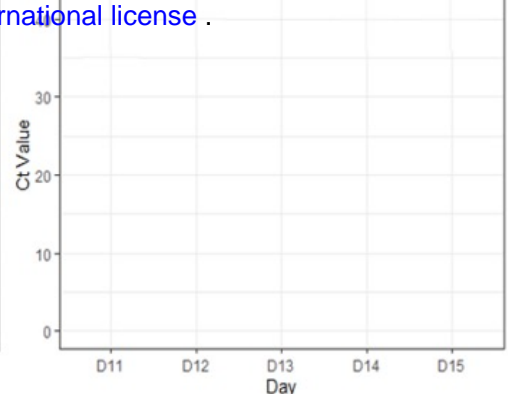

Aerosol Fraction

- Large

- Medium

Small

- Unlabelled

Ward

- ICU
Bioaerosol Classification

- Bacteria

A Fungi

- Virus

Bioaerosol Detected

- Candida spp.

- CoN Staph

- E. faecalis

- E. faecium

- Fungal $18 \mathrm{~S}$

- HSV1

P. mirabilis

- S. epidermidis

- S. pyogenes

SARS-CoV-2

- S. aureus
C

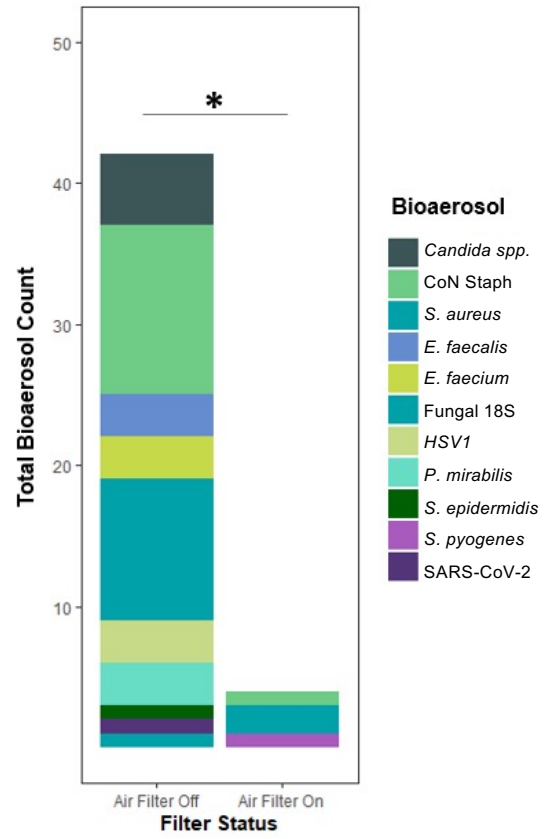

Figure 3. Bioaerosol detection in specific air sampler fractions over the three-week testing period on the 'surge' ICU.

A) $\mathrm{C}_{T}$ value for the single qPCR SARS-CoV-2 detection on day 9 (week 2) in the medium (1-4 $\mu \mathrm{m}$ particle size) fraction. B) Daily detection of fungal, bacterial and viral bioaerosol detected by high-throughput qPCR collected during weeks one (filter off) and two (filter on). The differences in $\mathrm{C}_{T}$ values between the regular qPCR (A) and high-throughput qPCR (B) are a function of the microfluidics technology, and do not reflect higher bioaerosol burdens. C) Stacked bar chart showing collated total number of bioaerosol detections during weeks one (filter off) and two (filter on). ${ }^{*} p=0.05$ by Mann-Whitney U test. 